Article

\title{
Rheological Properties with Temperature Response Characteristics and a Mechanism of Solid-Free Polymer Drilling Fluid at Low Temperatures
}

\author{
Sheng Wang ${ }^{1, *}$, Chaopeng Yuan ${ }^{1}$, Chuan Zhang ${ }^{2}$, Liyi Chen ${ }^{1}$ and Jiancheng Liu ${ }^{1}$ \\ 1 State Key Laboratory of Geohazard Prevention and Geoenvironment Protection, \\ Chengdu University of Technology, Chengdu 610059, China; damaodamo@sina.cn (C.Y.); \\ cly@cdut.edu.cn (L.C.); liujc90@163.com (J.L.) \\ 2 School of Civil Engineering, Southwest Jiaotong University, Chengdu 610031, China; \\ swjtuzhangchuan@outlook.com \\ * Correspondence: muyangren1215@sina.cn; Tel.: +86-28-8407-3193
}

Academic Editor: Giorgio Biasiol

Received: 6 October 2016; Accepted: 20 December 2016; Published: 23 December 2016

\begin{abstract}
The rheological properties of drilling fluid have important effects during drilling in natural gas hydrate at low temperatures. The present study was performed using theoretical analysis. Experiments and micro-analyses were carried out to determine the rheological properties with temperature response characteristics and the mechanism involved in solid-free polymer drilling fluid (SFPDF) at low temperatures when drilling in permafrost with natural gas hydrates (NGH). The curves of shear stress with the shear rates of three kinds of polymer drilling fluids, Semen Lepidii natural vegetable gum, polyacrylamide, and xanthan gum, were drawn. Then, statistical and related analyses of test data were performed using Matlab ver. 8.0. Through regression analysis, the Herschel-Bulkley model was used to characterize the rheological characteristics of SFPDF. On this basis, the laws regarding the rheological properties of the three kinds of SFPDF under changing temperatures were analyzed and rheological properties with temperature response state equations were established. Next, the findings of previous studies on rheological properties with temperature response characteristics of the SFPDF were reviewed. Finally, the rheological properties with temperature response mechanisms were assessed using scanning electron microscopy and infrared spectrum analysis.
\end{abstract}

Keywords: SFPDF; low temperature; Herschel-Bulkley model; rheological properties; response; microscopic characteristics

\section{Introduction}

Natural gas hydrates (NGH) represent a major source of untapped energy. This fuel is widely distributed, abundant, located at shallow depths, and clean burning. Permafrost provides one of the main sources of NGH [1,2]. China's Qinghai-Tibetan Plateau is rich in this source of NGH. Avoiding the melting of the permafrost is an important part of preserving the quality of the permafrost regions during the drilling process $[3,4]$.

The temperature in wells drilled in permafrost regions is the most important criterion related to the selection of drilling fluid, the performance of a drilling system, and the quantity of natural gas extracted. Temperature is also important when developing drilling programs, ensuring normal drilling, and preventing accidents. Using appropriate drilling fluid is critical to ensuring the normal regulation of well temperature [5]. The phase balance of NGH must be maintained in permafrost regions at high pressure and low temperatures. Under these conditions, as the temperature decreases, the basic 
rheological properties of the drilling fluid changes, and it has a tendency to condense [6]. Viscosity is also an important parameter of drilling fluid used in drilling into natural gas hydrate strata. An increase in the viscosity of drilling fluid can decrease its rheological properties under low-temperature conditions. The control of the rheological properties of drilling fluid, such as viscosity, is a principal issue during the extraction of NGH; it has a direct effect on whether drilling proceeds smoothly $[7,8]$.

During a study of drilling fluids used in NGH strata, Feng and Xu [9] performed experiments on ethylene glycol composite polymer drilling fluid. They found this type of fluid is resistant to change at low temperatures, as well as exhibiting desirable rheological properties and dehydration characteristics; this fluid was also effective in preventing collapse during orthogonal testing. They determined a suitable dosage of ethylene glycol and other polymers in the drilling fluid. Ning [10] analyzed globally-acquired research data related to low temperature stratum drilling. This study analyzed the characteristics of drilling and discussed the state of relevant research related to the use of low-temperature drilling fluid. Ning [10] also proposed a formula for drilling fluid, and discussed low-temperature stratum drilling. Tang [5] discussed the relationship between normal well drilling and temperature in wells when drilling in natural gas hydrate strata. That study determined the effects of different drilling fluids, discussed the relationship between well temperature regulation and drilling fluid freezing point, initial temperature, cycling time, as well as fluid type and properties. Wang [11] performed a study of the basic fluid used in low temperature drilling fluid. In this case, a $15 \% \mathrm{NaCl}$ solution was used as the basic fluid for low-temperature solid-free drilling fluid and that study found that this fluid could satisfy the requirements for drilling for natural gas hydrate in permafrost regions of the Qinghai-Tibetan Plateau.

Research has played a very important role in the promotion and technological development of natural gas hydrate drilling fluid. However, few studies have addressed the behavior of polymer drilling fluid at low temperatures, as well as the rheological properties with the temperature response laws of that fluid [12-15]. The main findings of those few studies are as follows: (1) experimental study of drilling fluid used to extract natural gas hydrate has focused on drilling in a marine settings; (2) less attention has been given to drilling for natural gas hydrate in permafrost regions and the related evaluation of the rheological properties of low-temperature drilling fluid; (3) the study of the formation of NGH has concentrated mainly on the inhibitory action; and (4) fewer experimental studies have been conducted related to the appropriate drilling fluid that can be used when drilling for natural gas hydrate in permafrost regions, as well as the rheological properties with temperature response characteristics of this type of drilling fluid.

Therefore, theoretical, experimental, and microscopic analyses were used to study the rheological properties with temperature response of three different types of SFPDF: Semen Lepidii natural vegetable gum (KL), polyacrylamide (PAM), and xanthan gum $(X C)$. Since KL for the vegetable gum, PAM for the synthetic polymer, and XC for the biopolymer are commonly used at present, using a six-speed rotatory viscometer, the curves of shear stress with shear rates under different temperature conditions were measured and drawn. In addition, a rheological model related to SFPDF was analyzed. Additionally, the laws for changes in rheological parameters in response to temperature were determined. Moreover, the rheological characteristics of this fluid and a temperature response state equation were established. In this way, the viscosity and temperature response characteristics of fluids used in the drilling of permafrost regions for NGH were studied. Finally, the mechanism underlying the rheological properties with temperature response mechanisms were analyzed using the infrared spectrum and a scanning electron microscope.

\section{Materials and Methods}

\subsection{Experimental Materials}

$\mathrm{NaCl}$ (pure chemicals), $\mathrm{NaOH}$ (pure chemicals), and polyacrylamide (pure chemicals) with a molecular weight of 3 million were obtained from Chengdu Shundali Polymer Company (Chengdu, 
Sichuan, China). Xanthan gum (XC), a kind of polysaccharide polymer generated by the effects of xanthan bacillus on carbohydrate, was obtained from Chengdu Kelong Chemical Co., Ltd. (Chengdu, Sichuan, China). Semen Lepidii natural vegetable gum (KL), for which the current research team holds a national patent, is a natural polymer derived from Semen Lepidii plant fruit and was produced by authors. GC, a linear macromolecular copolymer that incorporating cationic, anionic, and nonionic groups in the same molecular chain, is a copolymer of diethyldiallylammonium chloride with acrylamide and acrylic acid; it was also obtained from the Chengdu Shundali Polymer Company.

\subsection{Experimental Instruments}

The test instruments included: a JB50-D power electric mixer (Shanghai Qiwei Electronics Co., Ltd., Shanghai, China); ZNN-D6 six-speed rotatory viscometer and a marsh funnel (Qingdao Haitongda Special Instrument Factory, Qingdao, China); a FYL-YS-128L CNC cryopreservation refrigerator (Beijing Fu Yi Electrical Appliance Co., Ltd., Beijing, China) that can maintain a temperature in a range of $\pm 1{ }^{\circ} \mathrm{C}$, providing stable temperatures in the range of $15^{\circ} \mathrm{C}$ to $-30^{\circ} \mathrm{C}$; Fourier transform infrared spectrometer, Nicolet type 560, (Thermo Nicolet Corp., Madison, WI, USA); and a scanning electron microscope, JMS-5900-lv (Japan Electron Optics Lab. Co., Ltd., Tokyo, Japan).

\subsection{Experimental Methods}

\subsubsection{Measurement of Rheological Parameters}

At room temperature, a six-speed rotating viscometer was started at the selected shear rate and viscosity was recorded every $5 \mathrm{~min}$, providing generally stable readings. The four values were recorded after continuous recording. If the deviation of the arithmetic mean of the last three values with the first value was, at most, $5 \%$, the viscosity value for that shear rate was considered determined.

The low-temperature refrigerator was used to lower the temperature of the drilling fluid to freezing, as required. A six-speed rotating viscometer was used to assess the viscosity of the fluid at temperatures ranging from room temperature to $-15^{\circ} \mathrm{C}$ at $3{ }^{\circ} \mathrm{C}$ intervals using the same methods that had been employed at room temperature. The corresponding rheological parameter was then calculated using the test results.

\subsubsection{Evaluation of the Rheological Model}

Establishing a model is needed to quantitatively characterize the rheological properties of drilling fluid. In the past, these properties have usually been described using Bingham plastic, Power Law, Carson, or Herschel-Bulkley models (Table 1).

Table 1. Common rheological models of drilling fluid.

\begin{tabular}{ccccc}
\hline $\begin{array}{c}\text { Rheological } \\
\text { Model }\end{array}$ & $\begin{array}{c}\text { Bingham Plastic } \\
\text { Model }\end{array}$ & Power Law Model & Herschel-Bulkley Model & Carson Model \\
\hline Formula & $\tau=\tau_{0}+\mu_{\mathrm{p}} \gamma$ & $\tau=\mathrm{K} \gamma^{n}$ & $\tau=\tau_{\mathrm{y}}+\mathrm{K} \gamma^{n}$ & $\mathrm{~T}^{0.5}=\tau_{\infty}{ }^{0.5}+\eta_{\mathrm{c}}{ }^{0.5} \gamma^{0.5}$ \\
\hline $\begin{array}{c}\text { Parameter } \\
\text { elucidation }\end{array}$ & $\begin{array}{c}\tau_{0} \text { : Yield stress } \\
\mu_{\mathrm{p}} \text { : Plastic viscosity }\end{array}$ & $\begin{array}{c}n \text { : Flow behavior index } \\
\text { K: Consistency coefficient }\end{array}$ & $\begin{array}{c}\tau_{\mathrm{y}} \text { : Yield stress } \\
\mathrm{K} \text { : Flow behavior indices } \\
\text { : consistency coefficient }\end{array}$ & $\begin{array}{c}\tau_{\infty} \text { : Extremely high shear stress } \\
\eta_{\mathrm{c}} \text { : Carson dynamic shear }\end{array}$ \\
\hline
\end{tabular}

These models have different rheological properties and use different rheological parameters. The present study employed the Matlab version 8.0 (The MathWorks, Inc., Natick, MA, USA) software package for statistical analysis. A variety of temperatures were used to study the relationship between shear stress and shear rate regression and to analyze the three kinds of drilling fluid, KL, PAM and XC, with the drilling fluid system and the addition of treatment agents. A rheological model of SFPDF suitable for use in permafrost region drilling was established based on the goodness-of-fit $\left(R^{2}\right)$ and the sum of square errors (SSE). Then, based on the corresponding parameters of the rheological model, the rheological properties of the drilling fluid and of the temperature response laws were determined. 


\subsubsection{Microscopic Analysis of the Drilling Fluid}

Infrared spectrum analysis involves collecting appropriately-worked drilling fluid samples that have been mixed with $\mathrm{KBr}$, grinding and tableting the sample, and using Fourier transformation infrared detection to determine the infrared spectra of the sample. The wave number range was 4000-400 $\mathrm{cm}^{-1}$. This study employed scanning electron microscopy (SEM) to analyze samples; drilling fluid samples were immobilized on a metal sample platform using conductive double-sided adhesive agents. A sputter coater was used to spray gold onto the samples in a vacuum to render them observable under a scanning electron microscope using a $20 \mathrm{kV}$ electron beam in a mirror. Magnification was adjusted, and each sample was photographed to show its morphology.

\section{Results}

\subsection{Rheological Model of KL, PAM, and XC Drilling Fluids}

Based on previous studies [16], $1 \mathrm{~L} \mathrm{H}_{2} \mathrm{O}+15 \% \mathrm{NaCl}+0.5 \% \mathrm{NaOH}$ was the basic fluid selected for this experiment. The rheological properties of the three kinds of SFPDF, KL, PAM and XC, were studied. First, shear stress was tested at different shear rates and with different concentrations of these three kinds of fluid $(0.2 \% w / v, 0.4 \% w / v, 0.6 \% w / v$ and $0.8 \% w / v)$; Figure 1 shows the curves of shear stress for each shear rate.

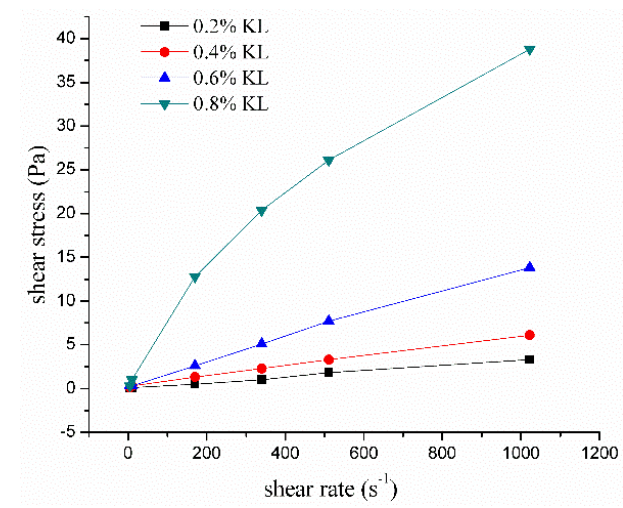

(a)

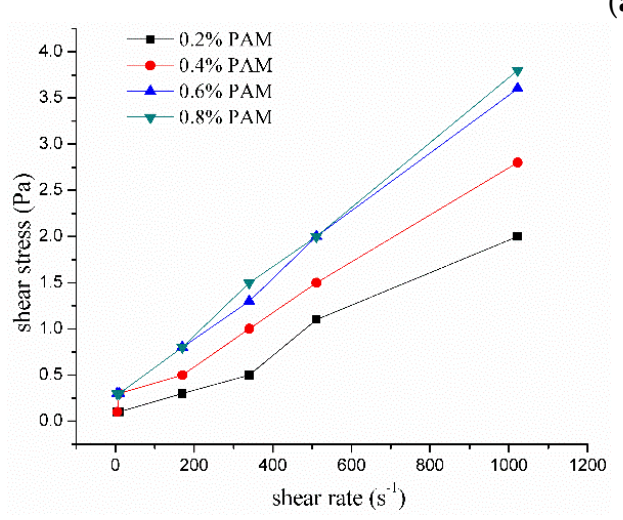

(b)

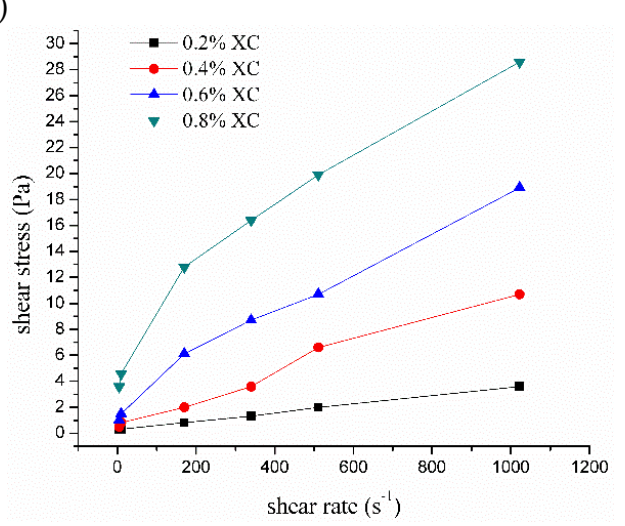

(c)

Figure 1. Shear stress with shear rate curves of different concentrations of Semen Lepidii natural vegetable gum $(\mathrm{KL})$, polyacrylamide (PAM), and xanthan gum (XC) drilling fluids. (a) KL drilling fluid rheological curve; (b) PAM drilling fluid rheological curve; and (c) XC drilling fluid rheological curve.

Rheological curves for the regression analysis of three kinds of different concentrations of polymer drilling fluid were drawn using linear regression and Bingham plastic, Power Law, Carson, and Herschel-Bulkley models (Figure 1 and Table 2). 
Table 2. Regression analysis of the degree of fitting $R^{2}$ and sum of square errors (SSE) for different concentrations of the three kinds of polymer drilling fluid.

\begin{tabular}{|c|c|c|c|c|c|c|c|c|c|c|c|c|c|}
\hline \multirow{2}{*}{ Concentration } & & \multicolumn{4}{|c|}{ KL (\%) } & \multicolumn{4}{|c|}{ PAM (\%) } & \multicolumn{4}{|c|}{ XC (\%) } \\
\hline & & 0.2 & 0.4 & 0.6 & 0.8 & 0.2 & 0.4 & 0.6 & 0.8 & 0.2 & 0.4 & 0.6 & 0.8 \\
\hline \multirow{2}{*}{ Bingham plastic model } & $R^{21}$ & 0.9931 & 0.9925 & 0.9961 & 0.9263 & 0.9843 & 0.9881 & 0.9889 & 0.9986 & 0.9981 & 0.9821 & 0.9763 & 0.9227 \\
\hline & $\operatorname{SSE}^{2}$ & 0.042 & 0.055 & 0.396 & 66.22 & 0.051 & 0.029 & 0.011 & 0.008 & 0.011 & 1.063 & 4.155 & 27.789 \\
\hline \multirow{2}{*}{ Power law model } & $R^{2}$ & 0.9934 & 0.9870 & 0.9986 & 0.9958 & 0.9785 & 0.9772 & 0.9793 & 0.9812 & 0.9796 & 0.9805 & 0.9885 & 0.9902 \\
\hline & SSE & 0.045 & 0.041 & 0.143 & 3.667 & 0.05 & 0.075 & 0.134 & 0.128 & 0.133 & 1.3805 & 1.998 & 3.258 \\
\hline \multirow{2}{*}{ Herschel-Bulkley model } & $R^{2}$ & 0.9958 & 0.9995 & 0.9989 & 0.9993 & 0.9958 & 0.9985 & 0.9975 & 0.9983 & 0.9979 & 0.9978 & 0.9926 & 0.9972 \\
\hline & SSE & 0.039 & 0.013 & 0.127 & 0.257 & 0.038 & 0.026 & 0.013 & 0.007 & 0.01 & 1.03 & 1.015 & 0.657 \\
\hline \multirow{2}{*}{ Carson model } & $R^{2}$ & 0.9933 & 0.9791 & 0.9983 & 0.9692 & 0.9615 & 0.9682 & 0.9901 & 0.9818 & 0.9703 & 0.9813 & 0.9843 & 0.9846 \\
\hline & SSE & 0.045 & 0.012 & 0.174 & 27.084 & 0.053 & 0.056 & 0.063 & 0.057 & 0.063 & 1.194 & 0.947 & 5.48 \\
\hline
\end{tabular}


The Herschel-Bulkley model is the ideal rheological model that can be used to characterize the rheological properties of solid-free polymer drilling fluid. The linear correlation coefficients $\left(R^{2}\right)$ found with all fluids tested here were greater than 0.99 and the sum of square errors (SSE) remained lower than others model for different kinds of drilling fluids and concentrate.

\subsection{Determination of the Quantities of KL, PAM, and XC}

The parameters of the Herschel-Bulkley model (apparent viscosity, yield stress, flow behavior indices, and consistency coefficient), were used here to characterize the rheological properties of SFPDF. Table 3 shows the rheological characterization of different concentrations of the three types of polymer drilling fluids.

Table 3. Rheological parameters of different concentrations of polymer drilling fluid.

\begin{tabular}{|c|c|c|c|c|c|c|c|}
\hline Fluid & Concentration & $\mathrm{AV}^{1}(\mathrm{mPa} \cdot \mathrm{s})$ & $\mathrm{YP}^{2}(\mathrm{~Pa})$ & $n^{3}$ & $\mathrm{~K}^{4}\left(\mathrm{~Pa} \cdot \mathrm{s}^{n}\right)$ & $R^{25}$ & $\operatorname{SSE}^{6}\left(\mathrm{~Pa}^{2}\right)$ \\
\hline $\mathrm{KL}^{7}$ & $0.2 \%$ & 3.3 & 0.1 & 0.9 & 0.1 & 0.9958 & 0.039 \\
\hline KL & $0.4 \%$ & 6.0 & 0.1 & 0.9 & 0.1 & 0.9995 & 0.013 \\
\hline KL & $0.6 \%$ & 13.5 & 0.3 & 0.9 & 0.1 & 0.9989 & 0.127 \\
\hline KL & $0.8 \%$ & 38.0 & 0.3 & 0.6 & 0.7 & 0.9993 & 0.257 \\
\hline $\mathrm{PAM}^{8}$ & $0.2 \%$ & 2.0 & 0.1 & 0.7 & 0.1 & 0.9958 & 0.038 \\
\hline PAM & $0.4 \%$ & 2.8 & 0.1 & 0.9 & 0.1 & 0.9985 & 0.026 \\
\hline PAM & $0.6 \%$ & 3.5 & 0.3 & 0.9 & 0.1 & 0.9975 & 0.013 \\
\hline PAM & $0.8 \%$ & 3.8 & 0.3 & 1.0 & 0.1 & 0.9983 & 0.007 \\
\hline$x C^{9}$ & $0.2 \%$ & 3.5 & 0.3 & 0.9 & 0.1 & 0.9979 & 0.01 \\
\hline $\mathrm{XC}$ & $0.4 \%$ & 10.5 & 0.5 & 0.7 & 0.1 & 0.9978 & 1.03 \\
\hline$X C$ & $0.6 \%$ & 18.5 & 1.0 & 0.9 & 0.1 & 0.9926 & 1.015 \\
\hline$X C$ & $0.8 \%$ & 28.8 & 3.6 & 0.6 & 0.4 & 0.9972 & 0.657 \\
\hline
\end{tabular}

${ }^{1}$ Apparent viscosity; ${ }^{2}$ Yield stress; ${ }^{3}$ Flow behavior index; ${ }^{4}$ Consistency coefficient; ${ }^{5}$ Goodness-of-fit; ${ }^{6}$ Sum of errors square; ${ }^{7}$ Semen lepidii natural vegetable gum; ${ }^{8}$ Polyacrylamide; ${ }^{9}$ Xanthan gum.

The yield stress parameter of the Herschel-Bulkley model, which represents the actual yield stress of the fluid, is represented here as the minimum shear stress required for the fluid to flow. Since yield stress is not extrapolated, the meaning of the yield stress in the Bingham model is different from that of the Herschel-Bulkley model parameter. The size of the yield stress value is primarily associated with the type and concentration of polymer treatment agent. In addition, the solids content of the fluid certainly influences the yield stress. The KL drilling fluid and PAM drilling fluid exhibited similar yield stress, while yield stress of the XC drilling fluid system was much greater than that of the other two fluids, and it increased with increasing concentration (Table 3).

Flow behavior indices (n) show that, within the scope of a certain shear rate, fluid behavior can be expressed by the strength of non-Newtonian forces. A smaller flow behavior index indicates a stronger Newton diagram of the drilling fluid and better performance of shear thinning. The value of the consistency coefficient $(\mathrm{K})$ is associated with drilling fluid viscosity and yield stress. A larger consistency coefficient indicates greater viscosity. Excessively large consistency coefficients can cause problems in the opening of a pump; if the consistency coefficient is too small, the fluid may carry rocky debris, creating a disadvantage. The values of flow behavior indices are mainly influenced by the formation of space truss structures. The consistency coefficient value is influenced by the solid phase content of the system and the viscosity of the liquid, it is also influenced by the strength of the fluid space grid structure. The flow behavior indices of the three kinds of system drilling fluids analyzed in the present study are comparatively high, and the consistency coefficient increases with an increasing concentration of the fluid's active ingredient (Table 3).

Suitable polymer concentrations [17] were determined as described in the analysis above, while considering the requirements of drilling in permafrost regions of the Qinghai Tibet Plateau for natural gas hydrate. That is, low-temperature SFPDF should be considered based on the findings of previous 
studies. The amounts of added KL, PAM, and XC should be $0.8 \%, 0.4 \%$ and $0.8 \%$, respectively, to create optimal drilling conditions; that is, drilling fluids showed suitable viscosities at these concentrations.

\subsection{Rheological Properties with Temperature Response Characteristics of SFPDF}

3.3.1. KL, PAM, and XC Drilling Fluid and Rheological Properties with Temperature Response Characteristics of SFPDF

Based on previous research and on the analysis given above, formulae were developed for the three types of SFPDF:

Sample 1: $1 \mathrm{~L} \mathrm{H}_{2} \mathrm{O}+15 \% \mathrm{NaCl}+0.5 \% \mathrm{NaOH}+0.8 \% \mathrm{KL}$
Sample 2: $1 \mathrm{~L} \mathrm{H}_{2} \mathrm{O}+15 \% \mathrm{NaCl}+0.5 \% \mathrm{NaOH}+0.4 \%$ PAM;
Sample 3: $1 \mathrm{~L} \mathrm{H}_{2} \mathrm{O}+15 \% \mathrm{NaCl}+0.5 \% \mathrm{NaOH}+0.8 \%$ XC;

The rheological parameters of the three samples were tested using a series of decreasing temperatures, and Figure 2 shows the curves of shear stress with the shear rate.

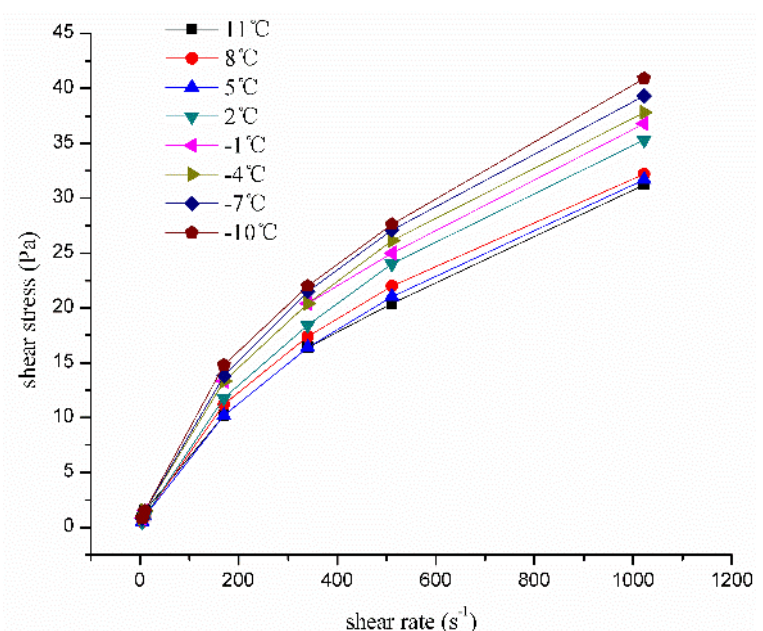

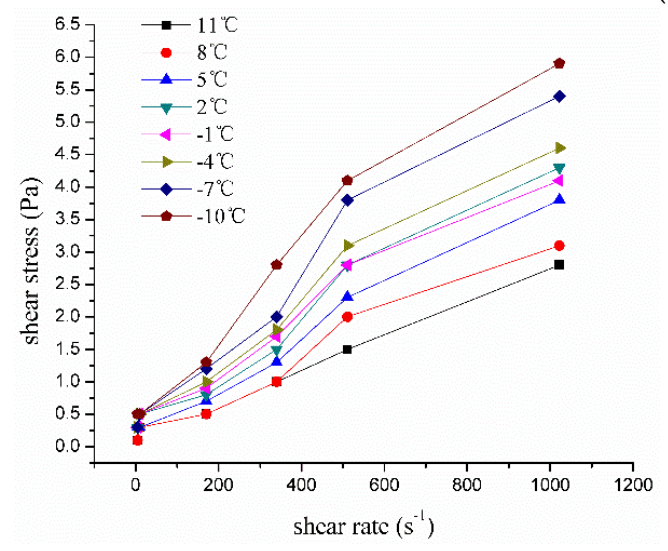

(b)

(a)

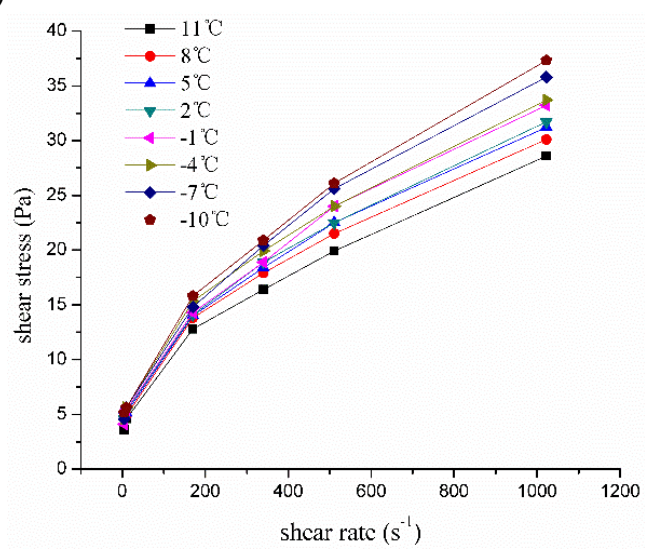

(c)

Figure 2. Shear stress with shear rate curves of three types of polymer drilling fluid at different temperatures. (a) Shear stress with shear rate curve of KL polymer drilling fluid shear stress with the shear rate curve; (b) Shear stress with the shear rate curve of PAM polymer drilling fluid; and (c) shear stress with the shear rate curve of XC polymer drilling fluid.

Figure 2 shows the fitting curve and Table 4 shows the goodness-of-fit $\left(R^{2}\right)$ and the sum of square errors (SSE) of four kinds of rheological models for the three kinds of drilling fluids. 
Table 4. Three kinds of polymer drilling fluid and the fit of the regression analysis $R^{2}$ and SSE.

\begin{tabular}{|c|c|c|c|c|c|c|c|c|c|c|}
\hline Temperature $\left({ }^{\circ} \mathrm{C}\right)$ & & & 10 & 7 & 4 & 1 & -2 & -5 & -8 & -11 \\
\hline \multirow{4}{*}{ Sample $1^{1}$} & BP model ${ }^{4}$ & $\begin{array}{c}R^{27} \\
\operatorname{SSE}^{8}\end{array}$ & $\begin{array}{l}0.9383 \\
68.988\end{array}$ & $\begin{array}{l}0.9163 \\
69.126\end{array}$ & $\begin{array}{l}0.9351 \\
77.344\end{array}$ & $\begin{array}{l}0.9269 \\
80.103\end{array}$ & $\begin{array}{l}0.9125 \\
33.530\end{array}$ & $\begin{array}{l}0.9171 \\
50.966\end{array}$ & $\begin{array}{l}0.9145 \\
37.524\end{array}$ & $\begin{array}{l}0.9176 \\
54.071\end{array}$ \\
\hline & PL model $^{5}$ & $\begin{array}{c}R^{2} \\
\text { SSE }\end{array}$ & $\begin{array}{c}0.9991 \\
2.656\end{array}$ & $\begin{array}{c}0.9954 \\
2.568\end{array}$ & $\begin{array}{c}0.9976 \\
3.216\end{array}$ & $\begin{array}{c}0.9961 \\
2.988\end{array}$ & $\begin{array}{c}0.9960 \\
0.539\end{array}$ & $\begin{array}{c}0.9966 \\
2.471\end{array}$ & $\begin{array}{c}0.9965 \\
1.300\end{array}$ & $\begin{array}{c}0.9965 \\
2.580\end{array}$ \\
\hline & $\mathrm{HB}$ model $^{6}$ & $\begin{array}{c}R^{2} \\
\text { SSE }\end{array}$ & $\begin{array}{c}0.9994 \\
0.247\end{array}$ & $\begin{array}{c}0.9993 \\
0.295\end{array}$ & $\begin{array}{c}0.9993 \\
0.388\end{array}$ & $\begin{array}{c}0.9993 \\
0.143\end{array}$ & $\begin{array}{c}0.9995 \\
0.222\end{array}$ & $\begin{array}{c}0.9991 \\
0.185\end{array}$ & $\begin{array}{c}0.9990 \\
0.157\end{array}$ & $\begin{array}{c}0.9992 \\
0.338\end{array}$ \\
\hline & Carson model & $\begin{array}{c}R^{2} \\
\text { SSE }\end{array}$ & $\begin{array}{l}0.9793 \\
27.168\end{array}$ & $\begin{array}{l}0.9663 \\
27.006\end{array}$ & $\begin{array}{l}0.9757 \\
30.772\end{array}$ & $\begin{array}{l}0.9704 \\
31.184\end{array}$ & $\begin{array}{l}0.9657 \\
11.195\end{array}$ & $\begin{array}{l}0.9676 \\
20.684\end{array}$ & $\begin{array}{l}0.9665 \\
14.064\end{array}$ & $\begin{array}{l}0.9675 \\
21.534\end{array}$ \\
\hline \multirow{4}{*}{ Sample $2^{2}$} & BP model & $\begin{array}{c}R^{2} \\
\text { SSE }\end{array}$ & $\begin{array}{c}0.9921 \\
0.029\end{array}$ & $\begin{array}{c}0.9657 \\
0.186\end{array}$ & $\begin{array}{c}0.9755 \\
0.109\end{array}$ & $\begin{array}{c}0.9737 \\
0.295\end{array}$ & $\begin{array}{c}0.9656 \\
0.282\end{array}$ & $\begin{array}{c}0.9636 \\
0.329\end{array}$ & $\begin{array}{c}0.9547 \\
0.699\end{array}$ & $\begin{array}{c}0.9486 \\
0.776\end{array}$ \\
\hline & PL model & $\begin{array}{c}R^{2} \\
\text { SSE }\end{array}$ & $\begin{array}{l}0.9815 \\
0.076\end{array}$ & $\begin{array}{c}0.9611 \\
0.212\end{array}$ & $\begin{array}{c}0.9653 \\
0.205\end{array}$ & $\begin{array}{c}0.9645 \\
0.446\end{array}$ & $\begin{array}{c}0.9534 \\
0.339\end{array}$ & $\begin{array}{c}0.9573 \\
0.387\end{array}$ & $\begin{array}{c}0.9616 \\
0.659\end{array}$ & $\begin{array}{c}0.9551 \\
0.533\end{array}$ \\
\hline & HB model & $\begin{array}{c}R^{2} \\
\text { SSE }\end{array}$ & $\begin{array}{c}0.9914 \\
0.027\end{array}$ & $\begin{array}{c}0.9549 \\
0.184\end{array}$ & $\begin{array}{c}0.9677 \\
0.109\end{array}$ & $\begin{array}{c}0.9697 \\
0.292\end{array}$ & $\begin{array}{c}0.9594 \\
0.219\end{array}$ & $\begin{array}{c}0.9562 \\
0.266\end{array}$ & $\begin{array}{c}0.9508 \\
0.565\end{array}$ & $\begin{array}{c}0.9495 \\
0.417\end{array}$ \\
\hline & Carson model & $\begin{array}{c}R^{2} \\
\text { SSE }\end{array}$ & $\begin{array}{c}0.9851 \\
0.056\end{array}$ & $\begin{array}{c}0.9636 \\
0.201 \\
\end{array}$ & $\begin{array}{l}0.9672 \\
0.160 \\
\end{array}$ & $\begin{array}{c}0.9736 \\
0.357\end{array}$ & $\begin{array}{c}0.9664 \\
0.242 \\
\end{array}$ & $\begin{array}{c}0.9631 \\
0.293 \\
\end{array}$ & $\begin{array}{c}0.9603 \\
0.597\end{array}$ & $\begin{array}{c}0.9584 \\
0.483 \\
\end{array}$ \\
\hline \multirow{4}{*}{ Sample $3^{3}$} & BP model & $\begin{array}{c}R^{2} \\
\text { SSE }\end{array}$ & $\begin{array}{l}0.9224 \\
27.789\end{array}$ & $\begin{array}{l}0.9206 \\
33.022\end{array}$ & $\begin{array}{l}0.9033 \\
30.995\end{array}$ & $\begin{array}{l}0.9246 \\
34.747\end{array}$ & $\begin{array}{l}0.9226 \\
37.963\end{array}$ & $\begin{array}{l}0.9153 \\
42.130\end{array}$ & $\begin{array}{l}0.9319 \\
39.438\end{array}$ & $\begin{array}{l}0.9425 \\
39.173\end{array}$ \\
\hline & PL model & $\begin{array}{c}R^{2} \\
\text { SSE }\end{array}$ & $\begin{array}{c}0.9903 \\
3.258\end{array}$ & $\begin{array}{c}0.9883 \\
3.498\end{array}$ & $\begin{array}{c}0.9887 \\
6.148\end{array}$ & $\begin{array}{c}0.9892 \\
3.909\end{array}$ & $\begin{array}{c}0.9922 \\
4.249\end{array}$ & $\begin{array}{c}0.9924 \\
3.628\end{array}$ & $\begin{array}{c}0.9903 \\
5.663\end{array}$ & $\begin{array}{c}0.9825 \\
7.212 \\
\end{array}$ \\
\hline & HB model & $\begin{array}{c}R^{2} \\
\text { SSE }\end{array}$ & $\begin{array}{c}0.9976 \\
0.658\end{array}$ & $\begin{array}{c}0.9997 \\
0.336\end{array}$ & $\begin{array}{c}0.9955 \\
0.582\end{array}$ & $\begin{array}{c}0.9993 \\
0.096\end{array}$ & $\begin{array}{c}0.9981 \\
0.602\end{array}$ & $\begin{array}{c}0.9993 \\
0.323\end{array}$ & $\begin{array}{c}0.9991 \\
0.260\end{array}$ & $\begin{array}{c}0.9967 \\
0.368\end{array}$ \\
\hline & Carson model & $\begin{array}{c}R^{2} \\
\text { SSE }\end{array}$ & $\begin{array}{c}0.9847 \\
5.480\end{array}$ & $\begin{array}{c}0.9865 \\
6.477\end{array}$ & $\begin{array}{c}0.9781 \\
5.229\end{array}$ & $\begin{array}{c}0.9863 \\
6.321\end{array}$ & $\begin{array}{c}0.9843 \\
7.482\end{array}$ & $\begin{array}{c}0.9822 \\
8.516\end{array}$ & $\begin{array}{c}0.9882 \\
6.721\end{array}$ & $\begin{array}{c}0.9911 \\
5.925\end{array}$ \\
\hline
\end{tabular}

\footnotetext{
${ }^{1} \mathrm{H}_{2} \mathrm{O}+15 \% \mathrm{NaCl}+0.5 \% \mathrm{NaOH}+0.8 \% \mathrm{KL} ;{ }^{2} \mathrm{H}_{2} \mathrm{O}+15 \% \mathrm{NaCl}+0.5 \% \mathrm{NaOH}+0.4 \%$ PAM; ${ }^{3} \mathrm{H}_{2} \mathrm{O}+15 \%$ $\mathrm{NaCl}+0.5 \% \mathrm{NaOH}+0.8 \% \mathrm{XC} ;{ }^{4}$ the Bingham plastic model $;{ }^{5}$ the Power Law model; ${ }^{6}$ the Herschel-Bulkley model; ${ }^{7}$ goodness-of-fit; ${ }^{8}$ the sum of square errors.
}

Regression analysis of the rheological curves for drilling fluid with three kinds of polymers at different temperature was carried out using linear regression. The Herschel-Bulkley model was still the most ideal rheological model for all of the types of polymer systems and at all of the temperatures studied here (Table 4 ) by comparing the $R^{2}$ and the SSE. This explains that the change in temperature did not change the rheological model of the drilling fluid system for SFPDF. For this reason, the Herschel-Bulkley model of the parameters was used to characterize the viscosity-temperature response law of solid-free polymer drilling fluid. Figure 3 shows the response curve that connects the data points based on this data.

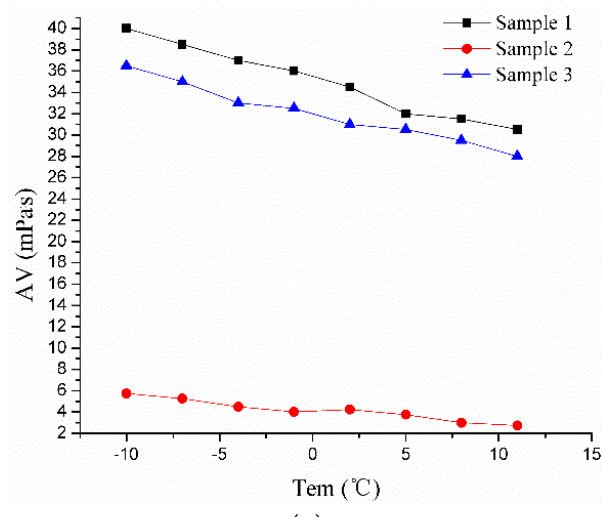

(a)

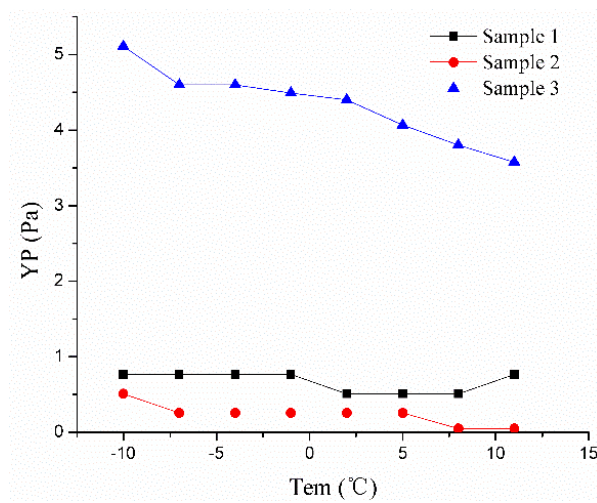

(b)

Figure 3. Cont. 


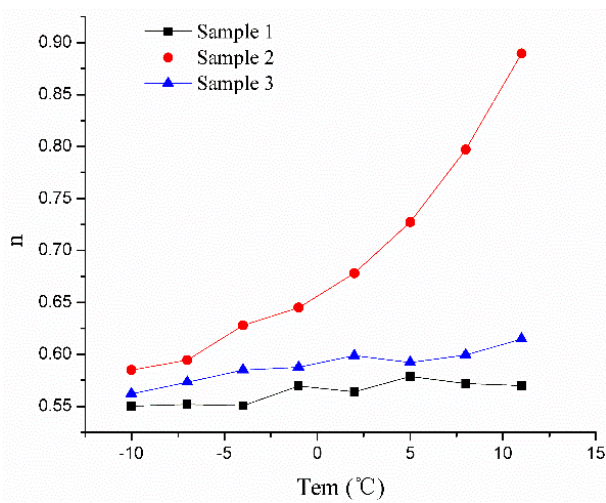

(c)

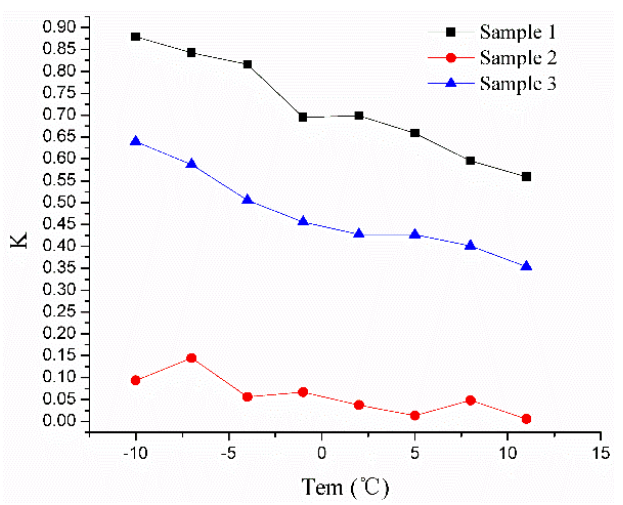

(d)

Figure 3. Rheological properties with temperature response curves of three kinds of solid-free polymer drilling fluid (SFPDF). (a) Apparent viscosity with the temperature response curve; (b) Yield stress with the temperature response curve; (c) Flow behavior index with the temperature response curve; and (d) Consistency coefficient with the temperature response curve.

A residual figure was produced using different functions of curve fitting (Figure 3). By comparison of the curve of apparent viscosity, yield stress, and consistency coefficient, the linear fitting of the residual distribution, as well as the trinary polynomial residual distribution of flow behavior indices, were both close to a normal distribution. In this way, a linear function curve fitting of apparent viscosity, yield stress, and consistency coefficient was drawn (Figure 3). A trinary polynomial function fitting the flow behavior indices was used and Table 5 shows the fitting equation.

Table 5. Rheological properties with temperature characteristic equations of three kinds of SFPDF.

\begin{tabular}{|c|c|c|c|c|c|c|c|c|c|c|c|c|}
\hline Parameter & $\mathrm{AV}^{1}$ & $R^{22}$ & $\operatorname{SSE}^{3}$ & ty ${ }^{4}$ & $R^{2}$ & SSE & $n^{5}$ & $R^{2}$ & SSE & $\mathrm{K}^{6}$ & $R^{2}$ & SSE \\
\hline Sample 1 & $y=35.23-0.47 x$ & 0.985 & 1.11 & $y=0.68-0.01 x$ & 0.913 & 0.09 & $\begin{array}{c}y=0.57+0.01 x+ \\
4 x^{2}-1.35 x^{3}\end{array}$ & 0.983 & 0.78 & $y=0.73-0.02 x$ & 0.961 & 0.003 \\
\hline Sample 2 & $y=4.22-0.14 x$ & 0.939 & 0.38 & $y=0.24-0.02 x$ & 0.969 & 0.04 & $\begin{array}{c}y=0.66+0.01 x+ \\
6.38 x^{2}+3.04 x^{3}\end{array}$ & 0.938 & 0.26 & $y=0.06-0.01 x$ & 0.961 & 0.005 \\
\hline Sample 3 & $y=32.19-0.38 x$ & 0.976 & 1.14 & $y=4.36-0.07 x$ & 0.934 & 0.09 & $\begin{array}{c}y=0.59+9.6 x- \\
5.64 x^{2}+1.44 x^{3}\end{array}$ & 0.988 & 0.38 & $y=0.48-0.013 x$ & 0.913 & 0.004 \\
\hline
\end{tabular}

Figure 3 and Table 5 shows the following:

(1) The apparent viscosities of the three polymer drilling fluids analyzed here were found to increase with decreasing temperature. In addition, the volume required for the PAM drilling fluid was found to increase slightly less than that of the KL drilling fluid and the XC drilling fluid. The apparent viscosity of the PAM drilling fluid was lower than that of the KL drilling fluid and the XC drilling fluid. The analysis above is completely consistent with the actual phenomenon that viscosity of the drilling fluids increased with temperature reduction. However, it was found by the above that increasing the extent of the viscosity of the drilling fluid by adding different treatment agents is not the same. It may be inferred that different treatments have different degrees of resistance to temperature reduction.

(2) Yield stress of the KL drilling fluid and the PAM drilling fluid are relatively low and showed little change as temperature decreased. However, the yield stress of the XC drilling fluid was relatively high, and tended to increase as temperature decreased. Yield stress as a parameter in the Herschel-Bulkley model can be understood as the flow ability of the drilling fluid at low shear rates. The size of the yield stress is mainly related to the type of polymeric treatment agent and its amount. Although the concentrations of KL and PAM are different in drilling fluids, the yield stress of $\mathrm{KL}$ and PAM drilling fluids was similar. The yield stress of XC drilling fluid is higher than KL drilling fluid even though the amount of XC and KL added in drilling fluids is the same. Preliminary analysis 
may show that the XC drilling fluid system has a stronger ability to form space frame structures between the polymers.

(3) The flow behavior indices of the KL drilling fluid and the XC drilling fluid remained almost steady. The described spatial structure that formed between the polymers did not change much as the temperature decreases, and the flow behavior indices of PAM drilling fluid decreased rapidly as temperature decreased. At low temperatures $\left(-10^{\circ} \mathrm{C}\right)$, all three polymer drilling fluids exhibited similar values for the flow behavior indices.

(4) As temperature decreased, the consistency coefficient values of the three polymer drilling fluids increased, generally, as follows: sample $1>$ sample $3>$ sample 2 . The amount of KL and XC which were added into the drilling fluids were greater than the amount of XC which was added into drilling fluid, so the consistency coefficient value of the PAM drilling fluid is the minimum. For the same amounts of KL and XC which were added into drilling fluids, different internal structures of the polymers may lead to differences in the intensity of the consistency coefficient values.

3.3.2. Addition of GC Treatment Agent and the Rheological Properties with Temperature Response Characteristics of SFPDF

Several research units cooperated to develop GC with the goal of solving problems inherent in drilling fluid systems used in permafrost regions in the Qinghai-Tibetan Plateau involving cryogenic technology to extract natural gas hydrate. The GC treatment agent (Based on the previous research foundation, the amount of $0.6 \%$ was identified) was combined with the three types of polymer drilling fluid described above to produce particular samples. These samples were adjusted to optimize the overall performance of the polymer drilling fluid. The results of adding GC polymer to drilling fluid samples were as follows:

$$
\begin{aligned}
& \text { Sample 4: } 1 \mathrm{~L} \mathrm{H}_{2} \mathrm{O}+15 \% \mathrm{NaCl}+0.5 \% \mathrm{NaOH}+0.8 \% \mathrm{KL}+0.6 \% \mathrm{GC} \\
& \text { Sample 5: } 1 \mathrm{~L} \mathrm{H}_{2} \mathrm{O}+15 \% \mathrm{NaCl}+0.5 \% \mathrm{NaOH}+0.4 \% \mathrm{PAM}+0.6 \% \mathrm{GC} \\
& \text { Sample 6: } 1 \mathrm{~L} \mathrm{H}_{2} \mathrm{O}+15 \% \mathrm{NaCl}+0.5 \% \mathrm{NaOH}+0.8 \% \mathrm{XC}+0.6 \% \mathrm{GC}
\end{aligned}
$$

The drilling fluid samples were analyzed for rheological properties with respect to their temperature response after the addition of a GC treatment agent and was determined, as shown in Figure 4.

Using the same method, by comparing the distribution of the residual in different functions, the curves in Figure 4 were used to select and fit functions that were close to a normal distribution

\begin{tabular}{|c|c|c|c|c|c|c|c|c|c|c|c|c|}
\hline Parameter & $\mathrm{AV}^{1}$ & $R^{22}$ & $\mathrm{SSE}^{3}$ & ty ${ }^{4}$ & $R^{2}$ & SSE & $n^{5}$ & $R^{2}$ & SSE & $K^{6}$ & $R^{2}$ & SSE \\
\hline Sample 4 & $y=85.07-1.39 x$ & 0.97 & 1.21 & $y=4.49-0.11 x$ & 0.929 & 0.47 & $\begin{array}{c}y=0.57-0.01 x- \\
7.97 x^{2}+2.34 x^{3}\end{array}$ & 0.938 & 0.03 & $y=1.47+0.04 x$ & 0.985 & 0.09 \\
\hline Sample 5 & $y=11.71-0.29 x$ & 0.978 & 0.61 & $y=0.16-0.01 x$ & 0.972 & 0.02 & $\begin{array}{c}y=0.85+0.01 \mathrm{x}- \\
1.21 x^{2}+1.05 x^{3}\end{array}$ & 0.9711 & 0.06 & $y=0.04-8 x$ & 0.951 & 0.02 \\
\hline Sample 6 & $y=51.65-0.54 x$ & 0.984 & 1.15 & $y=9.57-0.04 x$ & 0.955 & 0.31 & $\begin{array}{c}y=0.52+0.01 x- \\
1.2 x^{2}+2.49 x^{3}\end{array}$ & 0.963 & 0.03 & $y=0.93-8.06 x$ & 0.962 & 0.02 \\
\hline
\end{tabular}
(Table 6).

Table 6. Rheological properties with temperature characteristic equations of the SFPDF containing GC.

Figure 4 shows the following:

(1) The addition of GC had a pronounced effect on the apparent viscosity of the three kinds of polymer drilling fluid. The performance of the samples could be ranked as: Sample $4>$ Sample 6 $>$ Sample 5. As temperature decreased, the apparent viscosity of drilling fluid increased. Although overall viscosity was high, with respect to Figure 3a, after addition of the GC treatment agent, as the temperature decreases, the increasing trend of the drilling fluid viscosity is smaller, especially in the $\mathrm{XC}$ drilling fluid, where the temperature change has very little impact on the viscosity of the drilling fluid. Perhaps some kind of cross-linking between the polymers caused the temperature resistance 
ability to enhance after the addition of the GC treatment agent. Because the GC treatment agent was added in drilling fluid, the concentration of the polymer in the drilling fluids increased and the viscosity increased.

(2) The drilling fluid could be ranked by yield stress as: Sample $6>$ Sample $4>$ Sample 5. However, after addition of GC, these three systems of polymer drilling fluids showed only small increases in yield stress as the temperature decreased. After the GC treatment agent added in drilling fluid, as the temperature decreases, the grid structure between the polymers in the drilling fluid became more stable, the result is that the yield stress is also more stable. With respect to Figure $3 b$, yield stress increased due to the addition of the GC treatment agent in the drilling fluid, resulting in drilling fluid polymer concentration increases and, thus, an increase in yield stress.

(3) As temperature decreased, the flow behavior indices increased in both samples 4 and 6 , but it decreased slightly in Sample 5. The flow behavior indices of Sample 5 were larger than those in the other two systems, and close to a Newtonian fluid. The change range of Sample 4 and Sample 6 are not great, and the flow behavior indices are close to the average values in Figure 3c.

(4) The consistency coefficient remained stable as the temperature decreased in Samples 5 and 6, but the consistency coefficient decreased as temperature decreased in Sample 4. Compared to Figure 3d, the consistency coefficient has increased, but the trend as the temperature decreased is different. The consistency coefficient of the KL and XC drilling fluids with the added GC treatment agent have opposite trends. There are no clay particles in the solid-free drilling fluid and it is a polymer. Therefore, after the addition of the GC treatment agent, drilling fluid polymer concentration increases and, therefore, has an impact on the drilling fluid consistency coefficient value, resulting in the consistency coefficient value increasing. On the other hand, after the GC treatment agent added in drilling fluid, the consistency coefficient rises with temperature reduction. This phenomenon may indicate that it is caused by the increase of the internal polymer structure strength.

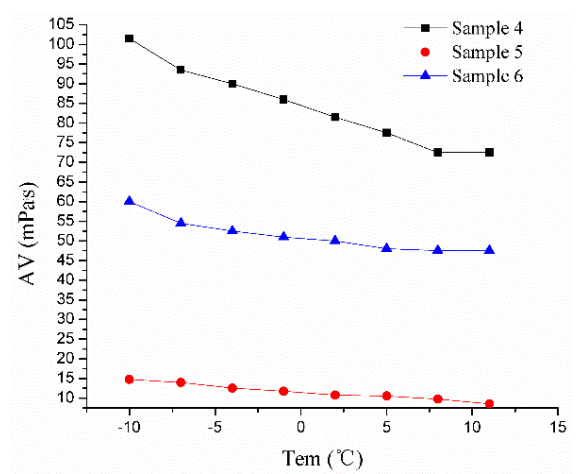

(a)

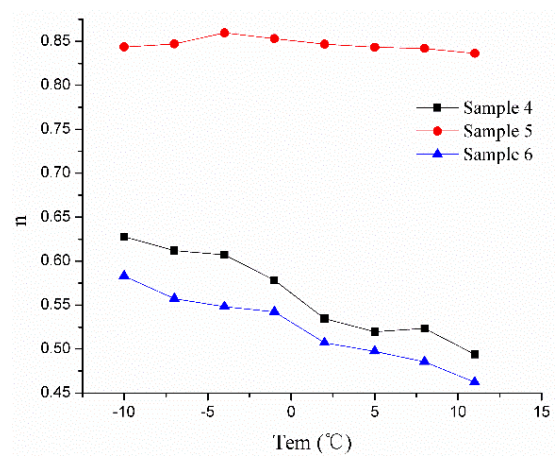

(c)

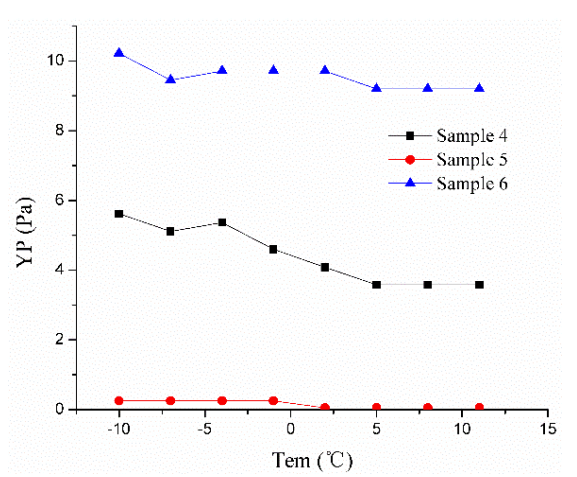

(b)

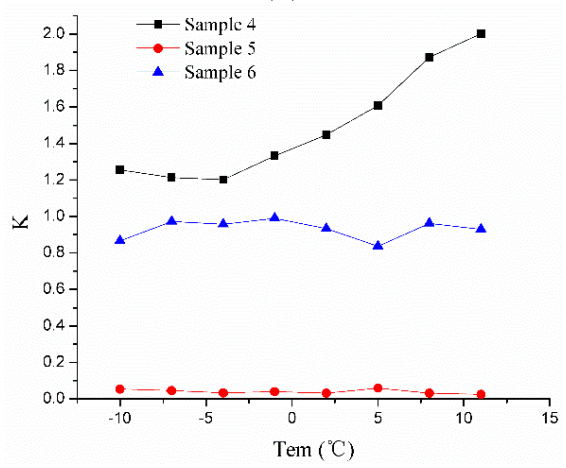

(d)

Figure 4. Rheological properties with temperature response curves of SFPDF containing the GC treatment agent. (a) AV with the temperature response curve; (b) YP with the temperature response curve; (c) $n$ with the temperature response curve; and (d) $\mathrm{K}$ with the temperature response curve. 


\subsection{Rheological Properties with Temperature Response Mechanisms in SFPDF}

\subsubsection{Fourier Transform Infrared Analysis}

The polymer drilling fluids were analyzed using infrared spectroscopy for Samples 4, 5, and 6 after the addition of the GC treatment agent (Figure 5).

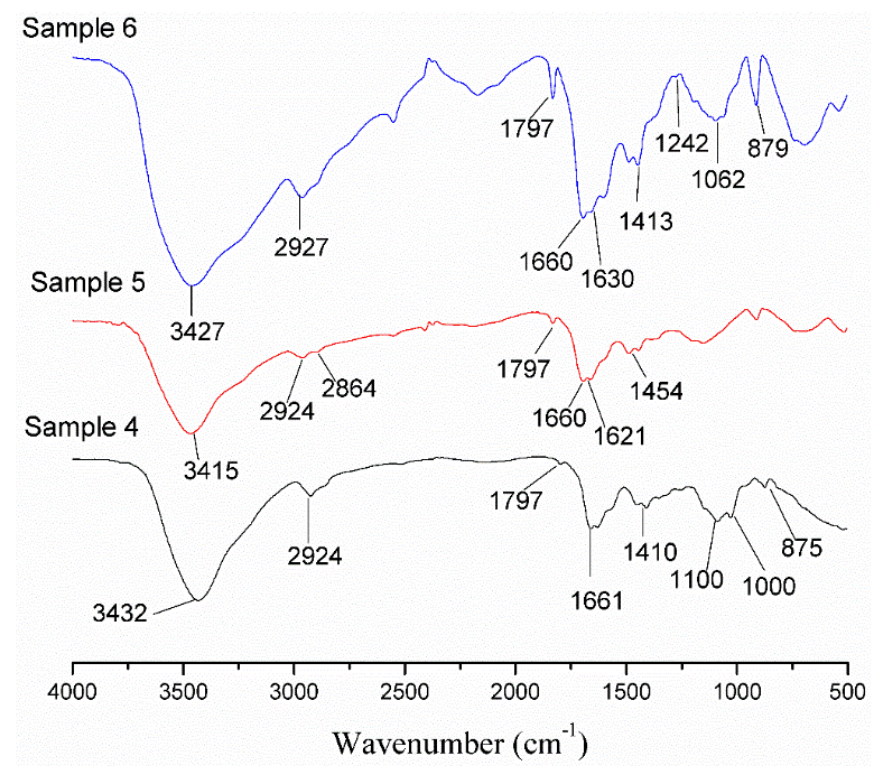

Figure 5. Infrared spectrum analysis of SFPDF containing the GC treatment agent.

Sample 4 in Figure 5 is the KL drilling fluid mixed with GC. The broad peaks at $3432 \mathrm{~cm}^{-1}$, $2924 \mathrm{~cm}^{-1}, 1797 \mathrm{~cm}^{-1}$ and $1661 \mathrm{~cm}^{-1}$ were attributable to $-\mathrm{OH}$, the methylene anti-symmetric stretching vibration characteristic absorption peak, the ester carbonyl stretching vibration, and the stretching vibration absorption peak of $\mathrm{C}=\mathrm{O}$, respectively. The stretching vibration of $\mathrm{C}-\mathrm{N}$ was visible at $1410 \mathrm{~cm}^{-1}$. At $1100-1000 \mathrm{~cm}^{-1}$ the vibration peak of primary and secondary hydroxyl C-O was visible for pyran mannose and galactose. At $875 \mathrm{~cm}^{-1}$ the vibration peak was a type of beta pyranose ring C-C vibration.

Sample 5 in Figure 5 is the PAM drilling fluid mixed with GC. The characteristic absorption peak for free $-\mathrm{NH}_{2}$ is visible at $3415 \mathrm{~cm}^{-1}$. The characteristic absorption peaks are visible at $2925 \mathrm{~cm}^{-1}$ and $2864 \mathrm{~cm}^{-1}$ for the methylene anti-symmetric and the methylene symmetric stretching vibrations. The ester carbonyl stretching vibration peak is visible at $1797 \mathrm{~cm}^{-1}$. The carbonyl characteristic absorption peak, corresponding to the amide I ( $\mathrm{C}=\mathrm{O}$ stretching vibration) is visible at $1660 \mathrm{~cm}^{-1}$. The characteristic peak for amide II (N-H bending vibration) is visible at $1621 \mathrm{~cm}^{-1}$. The methylene deformation characteristic absorption peak is visible at $1454 \mathrm{~cm}^{-1}$.

Sample 6 is XC drilling fluid mixed with GC (Figure 5). The broad peak at $3427 \mathrm{~cm}^{-1}$ is associated with $-\mathrm{OH}$. The methylene anti-symmetric and the ester carbonyl stretching vibrations are visible at $2927 \mathrm{~cm}^{-1}$ and $1797 \mathrm{~cm}^{-1}$, respectively. The characteristic stretching vibration peak at $1660 \mathrm{~cm}^{-1}$ is caused by $\mathrm{C}=\mathrm{O}$. The frame vibration absorption peak of the benzene ring is visible at $1630 \mathrm{~cm}^{-1}$. The absorption peak for pyruvic acid and acetyl reactive methyl bending vibration is visible at $1413 \mathrm{~cm}^{-1}$. The stretching vibrations for the six-member ring of $\mathrm{C}-\mathrm{O}$ and for $\mathrm{C}-\mathrm{O}$ in the ether bond are visible at $1242 \mathrm{~cm}^{-1}$ and $1062 \mathrm{~cm}^{-1}$, respectively. The characteristic peak for the pyran six-member sugar ring is visible at $879 \mathrm{~cm}^{-1}$.

As shown from the analysis, there were ester carbonyl stretching vibrations at $1797 \mathrm{~cm}^{-1}$ at the same time in the spectrum diagrams for all three samples of polymer drilling fluid. This group is visible in the elemental infrared image. This shows GC is very compatible with KL, PAM, and XC. Analysis 
also shows the three samples of polymers contain many hydrophilic groups; therefore, they are readily soluble in water because the hydrogen bonds facilitate molecular adsorption and combination.

\subsubsection{SEM Analysis}

Scanned electron microscopy images of powdered samples are presented for the three kinds of drilling fluid (Samples 4-6) magnified 1000× and 20,000× (Figure 6) showing the microstructure of these samples.

The microstructures of Samples 4 (Figure 6a) and 6 (Figure 6c) were relatively similar. The difference in the distribution of particle sizes was not great. However, Sample 4 , which contained $\mathrm{KL}$, had a large number of pores and relatively loose structure. Sample 6, which contained XC, appeared denser because the particles were curled up next to each other. The larger surface area of these two samples provided better adsorption and bridging than did Sample 5. Sample 5 (Figure 6b), with added PAM, exhibited a relatively flat surface structure, characterized by sheet formation. Even if the surface of the lamellar structure exhibited a relatively uniform distribution of convex particles, the surface area was far less than that of the other two samples. Thus, the physical and chemical properties of Sample 5 are different from Samples 4 and 6.
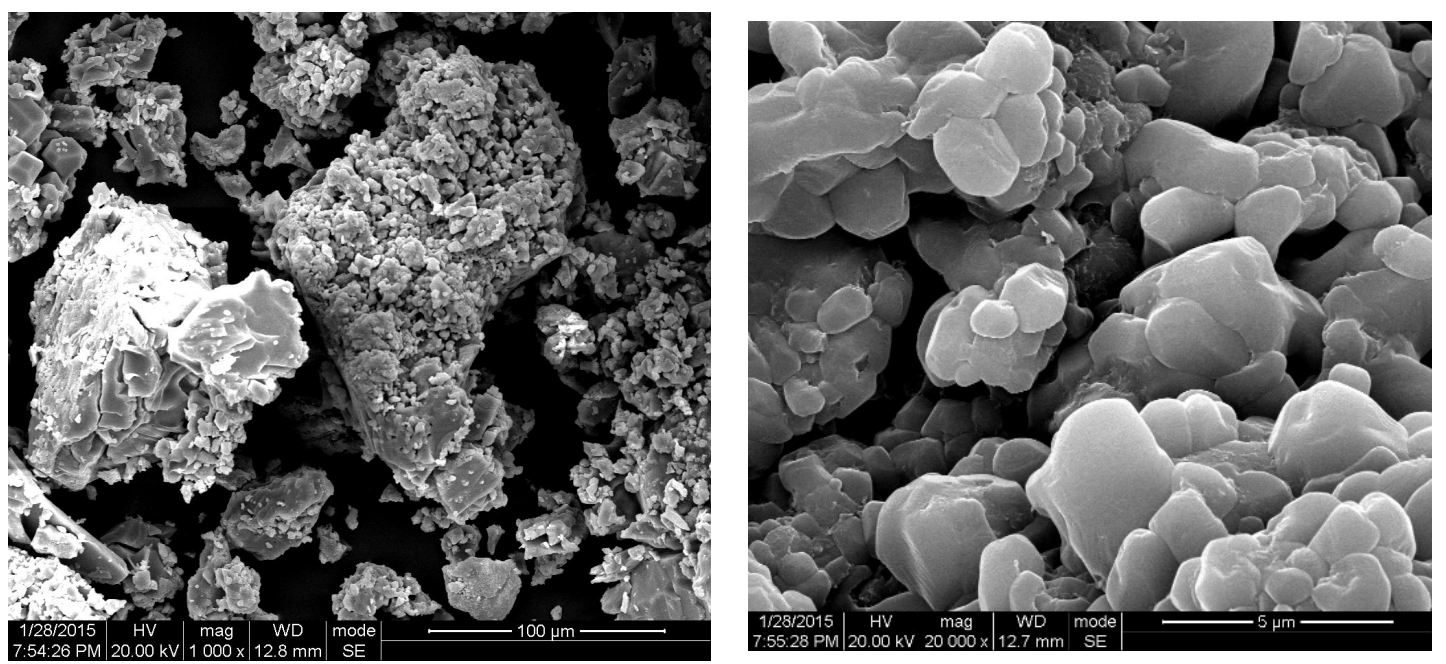

(a)
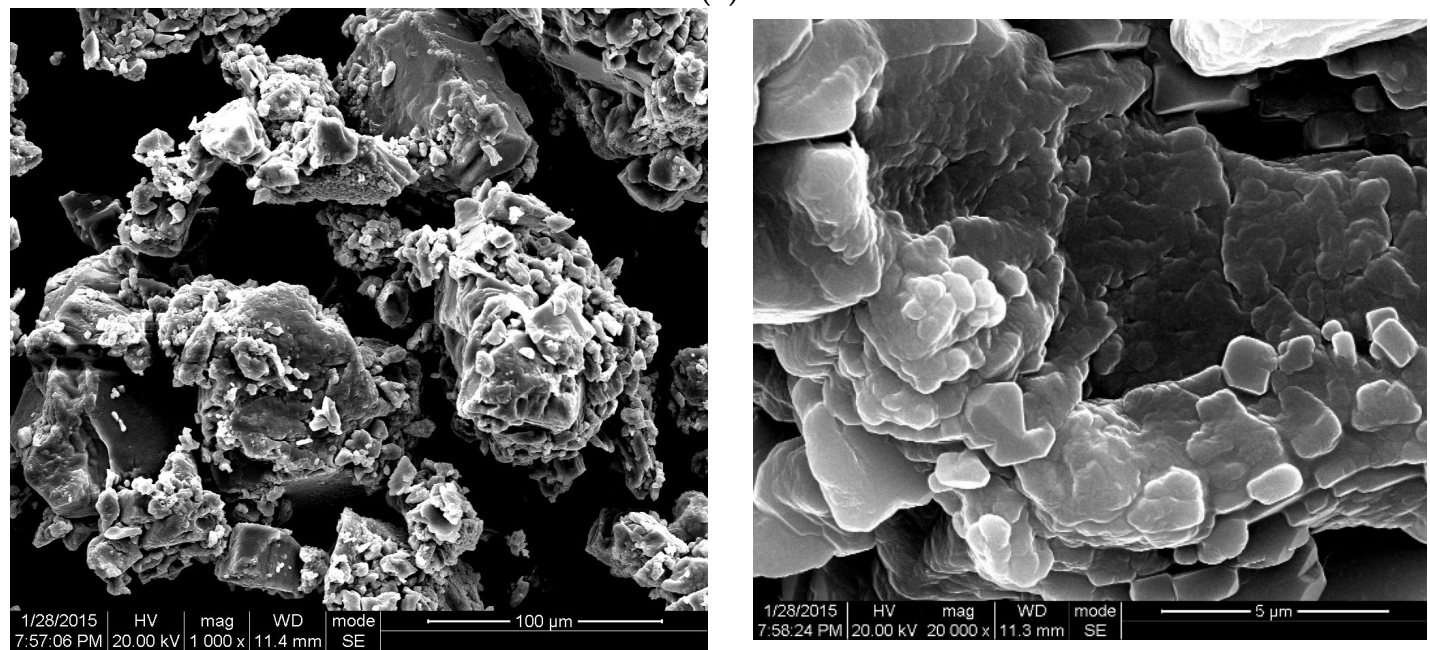

(b)

Figure 6. Cont. 

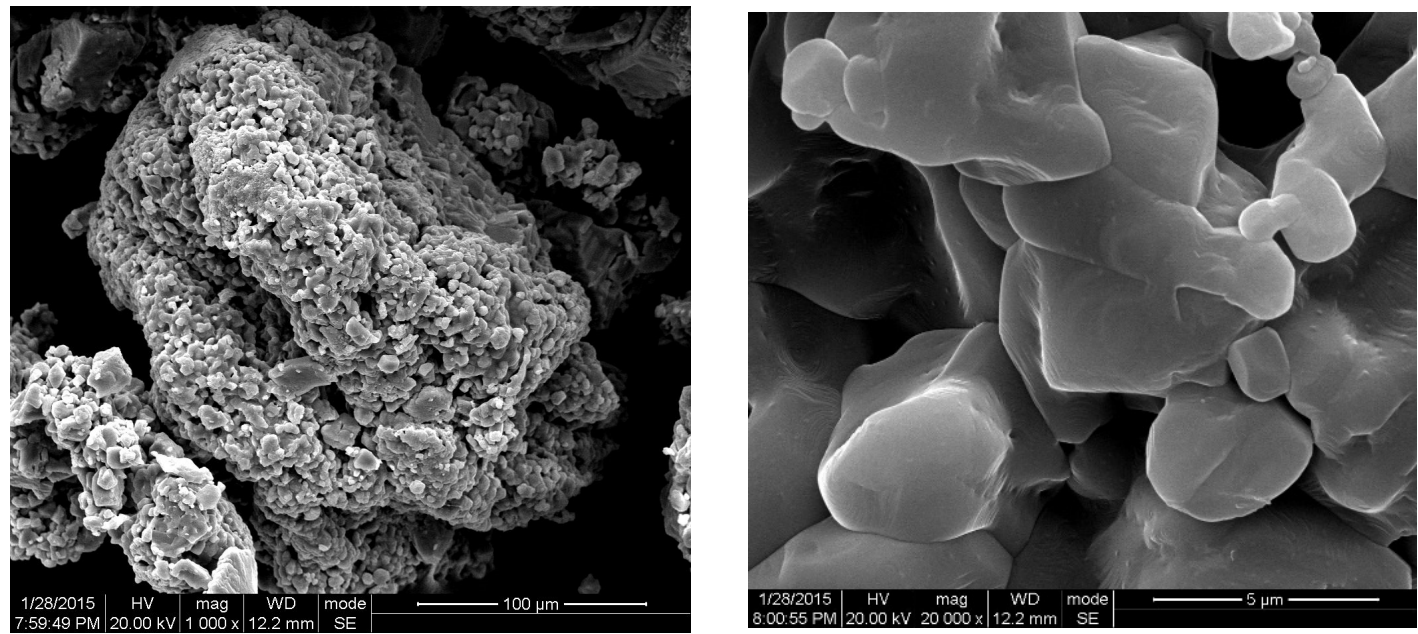

(c)

Figure 6. SEM results of SFPDF containing the GC treatment agent. (a) SEM results of the KL polymer drilling fluid; (b) SEM results of the PAM polymer drilling fluid; and (c) SEM results of the XC polymer drilling fluid.

\subsubsection{Discussion of Rheological Properties with Temperature Response Mechanisms}

Based on microscopic analysis and rheological testing of the drilling fluids, Samples 4 and 6 were found to be primarily polysaccharide polymers. In aqueous solution, $-\mathrm{OH}$ groups on molecular chains of polysaccharide polymers can adsorb water molecules through hydrogen bonding. This increases the contact and internal resistance to friction between the molecules, giving them greater viscosity. Due to the added inhibitor, $\mathrm{NaCl}$, the $-\mathrm{OH}$ group on molecular chain adhered to the -ONa group, and the adsorption of water molecules increased. At the same time, the addition of $\mathrm{NaOH}$ readily caused bonds in polysaccharide molecules to rupture, producing oligosaccharides. As the number of oligosaccharides increased, the point of contact between molecules and internal resistance to friction both increased. This made it easier for space truss structures to form, increasing the fluid viscosity and yield stress, and reducing the flow behavior indices. As temperature decreased, molecular kinetic energy decreased between polysaccharides, and the polysaccharide polymer crimps contracted. This reduces the production of the space grid structures, increasing viscosity, and weakening the rheological properties. In Sample 6, XC in water was added to the drilling fluid system. As a result, the polymer became capable of forming a double helix, which rendered the viscosity of the drilling fluid greater than that of the drilling fluid system containing KL (Sample 4).

PAM has 3 million molecular weight. While this polymer has a linear main chain, its rheological test indicated it has very low viscosity. Analysis of PAM showed a very weak ability to resist degradation by salt; therefore, after the addition of a large amount of $\mathrm{NaCl}$, the carboxylic acid group of the polyacrylamide molecule was blocked, causing the polyacrylamide molecule to take on a curly shape. This destroyed the polyacrylamide bridge and adsorption ability, thus, it was difficult to reach the original property.

Adding GC to Samples 4-6 modified the rheological properties of the drilling fluid. The apparent viscosity of the three samples with added GC was higher than in the samples without GC, and the rheological properties were undesirable. GC is a polymer, and in the absence of chemical reactions, KL, PAM, and XC are adsorbed through hydrogen bonding and mutual electrostatic forces between the molecules; this allows the formation of longer molecular chains with greater molecular weight in the drilling fluid. As a result, a long molecular chains containing more chain segments can form. To realize the heavy molecular weight of the migrating particles, it is necessary to complete the correct number of chain segments to facilitate synergy. At the same time, the long molecular chains become more seriously entangled, which increases the flow resistance; therefore, the shear viscosity of the polymer 
increases, the liquidity degrades, and apparent viscosity increases. As the temperature decreases, the energy involved in the molecular kinetics also decreases, and the polymers form tighter curls, slowing down the formation of space grid structures. All of this renders the viscosity higher than under normal temperatures.

\section{Conclusions}

This paper presents an experimental and analytical study for exploring the relationship between rheological properties and the temperature of SFPDF which were used for drilling in permafrost regions of the Qinghai Tibet Plateau for natural gas hydrate. Based on the results from experimental and mechanical analysis, it can be concluded that:

(1) Four different rheological models were chosen and regression analysis was used to study the rheological curve at different temperatures and different concentrations for SFPDF. The Herschel-Bulkley model was considered applicable and the model parameters were used to characterize the rheological properties of SFPDF.

(2) Rheological properties with temperature response characteristics of three types of SFPDF-KL, PAM and XC-and the system of SFPDF to which a GC treatment agent had been added were systematically analyzed. The rheological properties of different drilling fluids were evaluated. By obtaining the change laws of rheological properties with temperature, the foundation was built for the research of low-temperature drilling fluid.

(3) SEM examination and infrared spectrum analysis were used to analyze the rheological properties with the temperature response mechanism of the three kinds of SFPDF. These provided a good explanation for the viscosity of XC drilling fluid greater than that of the drilling fluid system containing $\mathrm{KL}$, and the drilling fluid with added GC modified the rheological properties.

Through the exploration of the SFPDF above, and the viscosity adjustment of the drilling fluid, the reference drilling fluid system for drilling in permafrost regions of the Qinghai Tibet Plateau for natural gas hydrate was supplied. The laws of drilling fluid at low temperature are proposed. For future research work, a study work on the research and development of a suitable treatment agent is proposed, but also, on perfecting the drilling fluid system in the present study will be conducted.

Acknowledgments: This paper has been supported by National Natural Science of China (Grant No. 41672362, 51204027), the Key projects of Sichuan Provincial Department of Education (Grant No. 16ZA0099) and the State Key Laboratory of Geohazard Prevention and Geoenvironment Protection (Grant No. SKLGP2012Z007, SKLGP2015Z010).

Author Contributions: Sheng Wang and Liyi Chen conceived and designed the experiments; Chuan Zhang and Chaopeng Yuan performed the experiments; Chuan Zhang and Chaopeng Yuan analyzed the data; Jiancheng Liu contributed materials and analysis tools; Sheng Wang and Chaopeng Yuan wrote the paper.

Conflicts of Interest: The authors declare no conflict of interest.

\section{References}

1. Sloan, E.D. Introductory Overview: Hydrate Knowledge Development. Am. Mineral. 2004, 89, 1155-1161. [CrossRef]

2. Ecker, C.; Nur, A.M.; Dvorkin, J. Estimating the Amount of Gas Hydrate and Free Gas from Marine Seismic Data. Geophysics 2000, 65, 565-573. [CrossRef]

3. Li, S.; Zhang, L.; Jiang, X.; Li, X. Hot-brine Injection for the Dissociation of Natural Gas Hydrates. Petroleum Sci. Technol. 2013, 31, 1320-1326. [CrossRef]

4. Sloan, E.D. Fundamental Principles and Applications of Natural Gas Hydrates. Nature 2003, 426, 353-359. [CrossRef] [PubMed]

5. Tang, F.L.; Zhang, S.D.; Jiang, G.S.; Кудряшов, Б.Б.; Wu, X.; Dou, B.; Gao, H. Dependence of Hole Temperature Distribution upon Drilling Fluid while Drilling in Frozen Formations Containing Natural Gas Hydrate. Geol. Sci. Technol. Inf. 2002, 21, 96-100.

6. Hege, E.; Majeed, Y.; Eirik, S. Hydrate Control during Deepwater Drilling: Overview and New Drilling-Fluids Formulations. SPE Drill. Complet. 2001, 6, 19-26. 
7. Watson, P.; Kolstad, E.; Borstmayer, R.; Pope, T.; Reseigh, A. An Innovative Approach to Development Drilling in the Deepwater Gulf of Mexico. World Oil 2004, 225, 41-48.

8. Rojas, J.C.; Daugherty, W.T.; Irby, R.D.; Bern, P.A.; Romo, L.A.; Dye, W.M.; Greene, B.; Trotter, R.N. New Constant-Rheology Synthetic-Based Fluid Reduces Downhole Losses in Deepwater Environments; SPE Annual Technical Conference and Exhibition; SPE: Anaheim, CA, USA, 2007.

9. Feng, Z.; Xu, H.W. Experimental Study on Ethylene Alcohol Multiplicity Polymer Drilling Fluid with Low Temperature Resistance. Glob. Geol. 2008, 27, 95-99.

10. Ning, F.L.; Wu, X.; Zhang, L. Experimental study on performance of water-based drilling fluid used to drill formations with gas hydrate. Nat. Gas Ind. 2006, 26, 52-55.

11. Wang, S.; Chen, L.Y.; Zhang, Y.Q. Development of Solids-free Low Temperature Drilling Fluid System: To be used for Natural Gas Hydrate Drilling in Tibet Plateau Permafrost. Nat. Gas Ind. 2009, 29, 59-62.

12. Kelland, M.A.; Mønig, K.; Iversen, J.E.; Lekvam, K. Feasibility Study for the Use of Kinetic Hydrate Inhibitors in Deep-Water Drilling Fluids. Energy Fuels 2008, 22, 2405-2410. [CrossRef]

13. Mehta, A.P.; Hebert, P.B.; Cadena, E.R.; Weatherman, J.P. Fulfilling the Promise of Low-Dosage Hydrate Inhibitors: Journey from Academic Curiosity to Successful Field Implementation. SPE Prod. Facil. 2003, 18, 73-79. [CrossRef]

14. Zhang, L.M.; Yin, D.Y. Preparation of a New Lignosulfonate-Based Thinner: Introduction of Ferrous Ions. Colloids Surf. A Physicochem. Eng. Aspects 2002, 210, 12-21. [CrossRef]

15. Zhang, G.B.; Wang, S.J.; Shi, P.Q. Researches and Applications of Viscosity Reducers for Drilling Fluids in China. Oilfield Chem. 2003, 17, 78-81.

16. Chen, L.; Wang, S.; Zhang, Y. Low Temperature Mud Basis Liquid of Gas Hydrate Drilling in Plateau Permafrost. Adv. Earth Sci. 2008, 23, 469-473.

17. Zhang, L.; Jiang, G.S.; Cai, J.H.; Dou, B.; Ning, F.L.; Tu, Y.Z. Overview of low temperature formation characteristics while drilling and available drilling fluid technology. Drill. Fluid Complet. Fluid 2006, 23, 73-76.

(C) 2016 by the authors; licensee MDPI, Basel, Switzerland. This article is an open access article distributed under the terms and conditions of the Creative Commons Attribution (CC-BY) license (http:/ / creativecommons.org/licenses/by/4.0/). 